\title{
Biodegradation Kinetics of Fragrances, Plasticizers, UV Filters, and PAHs in a MixtureChanging Test Concentrations over 5 Orders of Magnitude
}

Birch, Heidi; Sjøholm, Karina Knudsmark; Dechesne, Arnaud; Sparham, Chris; van Egmond, Roger; Mayer, Philipp

Published in:

Environmental Science and Technology

Link to article, DOI:

10.1021/acs.est.1c05583

Publication date:

2022

Document Version

Publisher's PDF, also known as Version of record

Link back to DTU Orbit

Citation (APA):

Birch, H., Sjøholm, K. K., Dechesne, A., Sparham, C., van Egmond, R., \& Mayer, P. (2022). Biodegradation Kinetics of Fragrances, Plasticizers, UV Filters, and PAHs in a MixtureChanging Test Concentrations over 5 Orders of Magnitude. Environmental Science and Technology, 56(1), 293-301.

https://doi.org/10.1021/acs.est.1c05583

\section{General rights}

Copyright and moral rights for the publications made accessible in the public portal are retained by the authors and/or other copyright owners and it is a condition of accessing publications that users recognise and abide by the legal requirements associated with these rights.

- Users may download and print one copy of any publication from the public portal for the purpose of private study or research.

- You may not further distribute the material or use it for any profit-making activity or commercial gain

- You may freely distribute the URL identifying the publication in the public portal 


\title{
Biodegradation Kinetics of Fragrances, Plasticizers, UV Filters, and PAHs in a Mixture-Changing Test Concentrations over 5 Orders of Magnitude
}

\author{
Heidi Birch,* Karina Knudsmark Sjøholm, Arnaud Dechesne, Chris Sparham, Roger van Egmond, \\ and Philipp Mayer
}

Cite This: Environ. Sci. Technol. 2022, 56, 293-301

Read Online

\section{ACCESS | Lلw Metrics \& More | 回 Article Recommendations | si Supporting Information}

ABSTRACT: Biodegradation of organic chemicals emitted to the environment is carried out by mixed microbial communities growing on multiple natural and xenobiotic substrates at low concentrations. This study aims to (1) perform simulation type biodegradation tests at a wide range of mixture concentrations, (2) determine the concentration effect on the biodegradation kinetics of individual chemicals, and (3) link the mixture concentration and degradation to microbial community dynamics. Two hundred ninety-four parallel test systems were prepared using wastewater treatment plant effluent as inoculum and passive dosing to add a

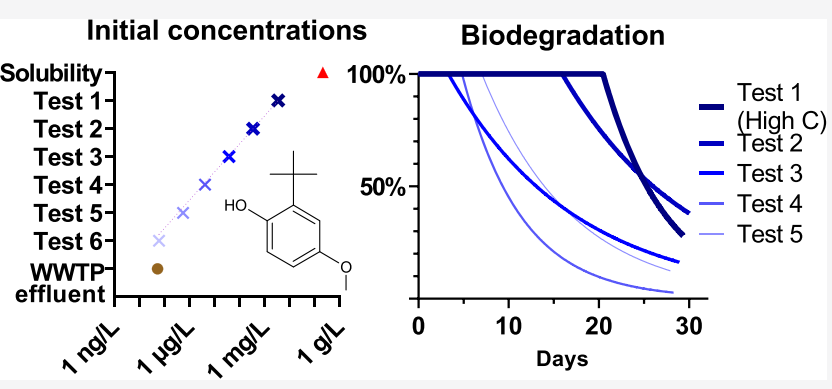
mixture of 19 chemicals at 6 initial concentration levels (ng/L to $\mathrm{mg} / \mathrm{L})$. After $1-30$ days of incubation at $12{ }^{\circ} \mathrm{C}$, abiotic and biotic test systems were analyzed using arrow solid phase microextraction and GC-MS/MS. Biodegradation kinetics at the highest test concentrations were delayed for several test substances but enhanced for the reference chemical naphthalene. Test concentration thus shifted the order in which chemicals were degraded. $16 \mathrm{~S}$ rRNA gene amplicon sequencing indicated that the highest test concentration $(17 \mathrm{mg} \mathrm{C} / \mathrm{L}$ added $)$ supported the growth of the genera Acidovorax, Novosphingobium, and Hydrogenophaga, whereas no such effect was observed at lower concentrations. The chemical and microbial results confirm that too high mixture concentrations should be avoided when aiming at determining environmentally relevant biodegradation data.

KEYWORDS: xenobiotics, simulation biodegradation, concentration effect, microbial community, passive dosing, $16 S$ rRNA, sequencing

\section{INTRODUCTION}

Biodegradation of chemicals in the environment is a complex process that depends on the chemicals, the microbial community, and many environmental factors. ${ }^{1}$ It is an important fate process for many chemicals and biodegradation data are, therefore, needed for the risk assessment and regulation of chemicals. Many formats exist for biodegradation tests differing in complexity, ranging from standardized screening tests for ready biodegradability, ${ }^{2}$ simulation tests for biodegradation in different environmental compartments, ${ }^{3,4}$ to non-standardized tests used for specific research purposes or difficult-to-test chemicals. ${ }^{5-7}$ Interest in the differences between standard tests and the more complex conditions in the field is not new ${ }^{8,9}$ but has increased lately. ${ }^{10-15}$ The environment is characterized by the presence of complex microbial communities, multiple substrates, and xenobiotics at low concentrations. Although, the relationship between the concentration of a single substrate and growth of a degrader population has long been described, ${ }^{16}$ much less is known about the concentration effect on biodegradation kinetics for mixtures at very low chemical concentrations in complex microbial communities.

The effect of substrate concentration on the population density of a single degrader strain and on the mineralization of the substrate can be described by the Monod kinetics (eq 1$)^{17}$

$$
-\mathrm{d} S / \mathrm{d} t=\mu_{\max } \cdot S\left(S_{0}+X_{0}-S\right) /\left(K_{\mathrm{S}}+S\right)
$$

where $S$ is the substrate concentration, $S_{0}$ is the initial substrate concentration, $\mu_{\max }$ is the maximum specific growth rate of the microbial population, $K_{\mathrm{S}}$ is the half-saturation constant for growth, and $X_{0}$ is the amount of substrate required to produce the initial population density (population density divided by yield). Equation 1 can be simplified in a number of ways depending on the initial microbial population density and

Received: August 20, 2021

Revised: December 3, 2021

Accepted: December 9, 2021

Published: December 22, 2021

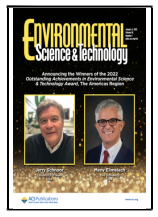


substrate concentrations. ${ }^{17}$ In situations where the chemicals do not cause growth of the microbial population, the chemical concentration may still affect the rate of biodegradation through enzyme interactions as described by MichaelisMenten kinetics. ${ }^{18}$ In both cases, below a certain substrate concentration (Simkins and Alexander ${ }^{17}$ found this shift to be around $1 \mathrm{mg} / \mathrm{L}$ for Monod kinetics), the chemical will be degraded according to first-order kinetics with the degradation rate proportional to the chemical concentration, if a sufficient density of degrader organisms and enzymes are present. Otherwise, it will be degraded according to the logistic model that includes the initial production of enzymes or growth of the degrader organism. ${ }^{17}$ The logistic model can be approximated by a lag phase followed by a first-order degradation phase, where the lag phase may cover the growth, enzyme production, and/or various adaptation processes. At higher concentrations, a stagnation of the increase in the biodegradation rate is expected because of limitations on the growth of degraders or due to enzyme saturation. ${ }^{17,18}$ This pattern is complicated by the possibility for substrate inhibition (toxicity) that can lower the rate of biodegradation at high substrate concentrations. $^{19,20,31}$ These descriptions predict the proportionality between the chemical concentration and degradation rate found at low concentration to remain intact when decreasing concentrations even further. However, van Bergen et al. ${ }^{21}$ found higher degradation rate constants in activated sludge at $30 \mathrm{nM}$ compared to $3 \mathrm{nM}$ for a number of pharmaceuticals. Boethling and Alexander ${ }^{8}$ also observed that for two of four test chemicals (2,4-D and carbaryl) degradation rates in stream water decreased more than expected at the lowest concentrations used (low $\mu \mathrm{g} / \mathrm{L}){ }^{8}$ Given longer incubation times $(18$ days), the chemicals were eventually degraded; however, they suggested that below a certain concentration threshold the proportionality between the concentration and degradation rate no longer applies. ${ }^{8}$ Toräng et al. ${ }^{22}$ likewise observed a threshold in the low $\mu \mathrm{g} / \mathrm{L}$ concentration range for MCPP and 2,4-D below which no adaptation of the microbial consortia occurred, and below which only a very slow biodegradation was seen in sediments and groundwater. ${ }^{22}$ Above this threshold, selective growth of specific degraders were observed. $^{22}$ However, no threshold was found for phenanthrene and fluoranthene down to low $\mathrm{ng} / \mathrm{L}$ concentrations in a study using a single strain inoculum ${ }^{23}$ or for 2-methylnonane and 1,2,4-trimethylbenzene at concentrations down to the low $\mu \mathrm{g} / \mathrm{L}$ or high $\mathrm{ng} / \mathrm{L}$ range in a study using stream water as inoculum. ${ }^{24}$ Also, Egli, ${ }^{25}$ described how microorganisms can use "mixed substrate growth" to survive in natural waters where the substrate is scarce and thus grow on a mixture of chemicals present at very low concentrations.

Standardized tests are conducted on single chemicals and vary in test concentrations from high $\mathrm{mg} / \mathrm{L}$ concentrations in screening tests to low $\mu \mathrm{g} / \mathrm{L}$ concentrations in simulation tests (the OECD 309 guideline recommends testing at two different test concentrations - typically 1 order of magnitude apart), ${ }^{4}$ whereas actual environmental concentrations may be much lower. Previously, the only way to generate biodegradation data at low concentrations was to use ${ }^{14} \mathrm{C}$-labeling, which implies the testing of one chemical at a time. However, recent advances in automated pre-concentration and instrumental analysis have improved the possibility for targeted analysis at very low concentrations. ${ }^{26}$ Furthermore, a new biodegradation approach for determining the primary biodegradation of chemicals in mixtures at low concentrations was recently developed. ${ }^{6}$ It allows simultaneous testing of many chemicals including hydrophobic and/or volatile chemicals. ${ }^{27}$ The combination of this biodegradation approach and targeted arrow solid phase microextraction (Arrow-SPME) coupled with $\mathrm{GC}-\mathrm{MS} / \mathrm{MS}$ analysis opens up the potential for determining the primary biodegradation kinetics of mixtures of test chemicals at very low $(\mathrm{ng} / \mathrm{L})$ concentrations.

In standard biodegradation tests, there are no requirements to characterize the inoculum, and the microbial community dynamics during incubation is thus often unknown. Recently, Southwell et al. ${ }^{10}$ studied the change in bacterial communities of freshly collected sediment and river water ( 8 sampling times over 2 years) and their development during incubation in OECD 308 and 309 tests. They found that though bacterial communities varied over time and also changed during incubation, there was no clear link between the microbial composition and the variation in the degradation rate of isopyrazam at relatively low concentration $(0.1 \mathrm{mg} / \mathrm{L}){ }^{10}$ However, the lack of inoculum characterization has been identified as a challenge for understanding the differences seen between biodegradation studies, and Kowalczyk et al. ${ }^{28}$ called for the use of molecular microbial ecology methods in biodegradation testing.

The aims of this study are, therefore, to (1) perform parallel biodegradation tests changing mixture concentrations over 5 orders of magnitude, (2) determine the effect of mixture concentration on the biodegradation kinetics of individual chemicals, and (3) link the mixture concentration and degradation to bacterial community dynamics during incubation. Fragrances, plasticizers, UV filters, and reference chemicals [including two polyaromatic hydrocarbons (PAHs)] were included in the test mixture to cover some of the diversity of chemical structures in wastewater treatment plant influent and effluent. Six parallel biodegradation experiments were conducted spanning 5 orders of magnitude in concentration of individual test substances and maintaining the composition of the added mixture.

\section{EXPERIMENTAL SECTION}

Materials. Test chemicals were chosen among current and previously used chemicals in personal care products in order to cover a diverse set of chemical structures, taking analytical constraints into account. The test chemicals citronellol, dibutyl phthalate, dicyclohexyl phthalate, drometrizole, 2-ethylhexyl 4methoxycinnamate, 2-ethylhexyl salicylate, geraniol, homosalate, linalool, musk ketone, tonalide, and 4-tert-butylcyclohexyl acetate were purchased from Sigma-Aldrich (Copenhagen, Denmark), and $\alpha$-isomethylionone, oxacycloheptadec-10-en-2one, and tert-butyl-4-methoxyphenol were provided by Global Product Compliance Europe AB (Lund, Sweden). Four reference chemicals were included in the study: 1,3,5trichlorobenzene as a poorly degradable chemical, anthraquinone as an inherently degradable chemical, ${ }^{29}$ and naphthalene and phenanthrene that were degraded in our earlier studies. ${ }^{6,30}$ The four reference chemicals were purchased from SigmaAldrich (Copenhagen, Denmark). The purity of chemicals was $>95 \%$. Translucent silicone rods (3 $\mathrm{mm}$ in diameter) were custom made by Altec (St Austell, UK, product code 1368380) and used for passive dosing. Ethyl acetate (SigmaAldrich, $\geq 99.7 \%$ ) and ethanol (VWR chemicals, 99.8\%) were used for cleaning the silicone rods. Ultrapure water was produced using an Elga PURELAB flex water system (Holm \& Halby, Denmark). 


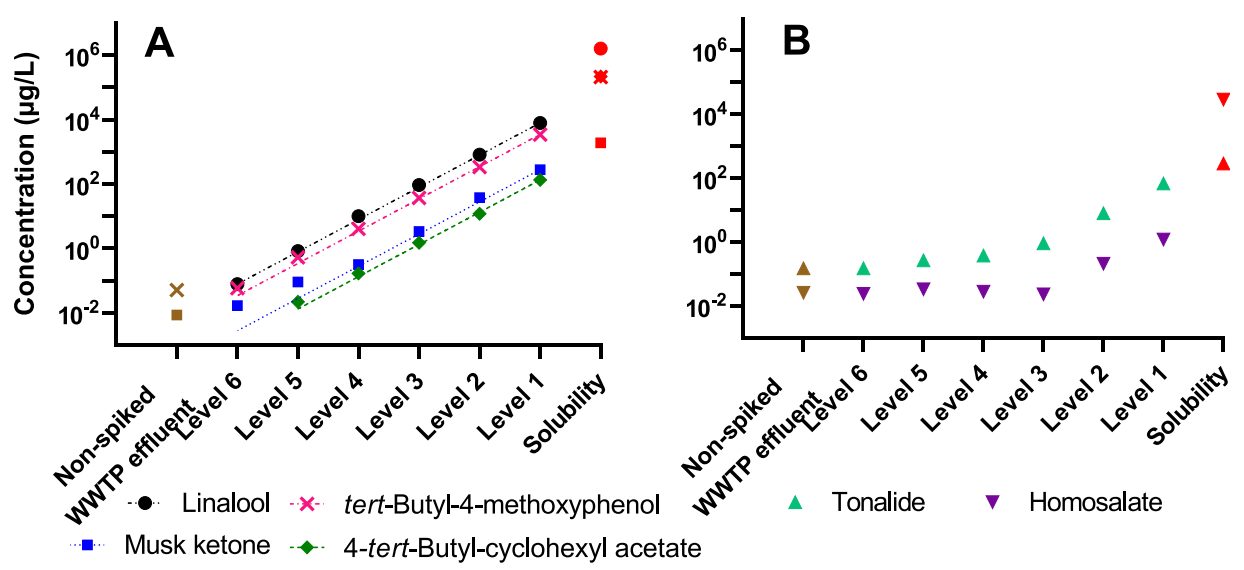

Figure 1. Initial test concentration in the six parallel biodegradation tests, non-spiked WWTP effluent concentration (brown symbols), and solubility (red symbols) [experimental or estimated values from the Danish (Q)SAR Database ${ }^{46}$. Fitted linear factor 10 lines are indicated (stippled) on A. Standard error of mean (SEM) error bars $(n=3)$ are smaller than symbols for all data points.

Inoculum. Effluent from a large wastewater treatment plant (WWTP effluent) in the Copenhagen area was used as inoculum (Spildevandscenter Avedøre treated 25,7 mio $\mathrm{m}^{3}$ wastewater in $2019^{35}$ from approximately 250,000 citizens). Effluent was chosen as a relevant inoculum to study the concentration effects because its microbial composition has a high impact on the microbial composition of the receiving streams. ${ }^{36}$ WWTP effluent was sampled on the 8th of June 2020 from an open channel at the treatment plant, transported to the lab in insulated bags, and stored at $12{ }^{\circ} \mathrm{C}$ during the setup of the experiments (setup completed within $12 \mathrm{~h}$ of sampling). Background characterization of the effluent is shown in Table S1.

Biodegradation Experiments. Six parallel biodegradation experiments were conducted spanning 5 orders of magnitude in concentration of each test chemical added to the wastewater treatment plant effluent. The added concentration levels for test substances were based on (1) keeping concentrations of all substances below the respective water solubilities, (2) ensuring analytical sensitivity for most of the concentration levels, (3) a maximum acceptable biological oxygen demand of the mixture to ensure aerobic conditions, and (4) a wish to extend the higher levels into the baseline toxicity range because that could affect degradation kinetics. ${ }^{31}$ Concentration levels were prepared with a spacing of 1 order of magnitude between each concentration level. The chosen highest concentration and the analytical detection limits of the chemicals thus allowed up to 6 concentration level to be included. Measured concentrations in test systems ranged from 1 to $8000 \mu \mathrm{g} / \mathrm{L}$ in the highest concentration experiment (level 1) down to 0.6$80 \mathrm{ng} / \mathrm{L}$ in the lowest concentration experiment (level 6) (Figures 1 and S1).

Passive dosing was used to add the test chemicals to biodegradation test systems below their water solubility and without the addition of a co-solvent. ${ }^{23,32,33}$ Passive dosing systems contained silicone rods loaded with test chemicals. The highest biodegradation test concentration was prepared by the equilibration of the loaded rods with wastewater treatment plant effluent. This solution was then transferred to biodegradation test systems for test initiation. Lower test concentrations were achieved by equilibrating the rod with pure water and spiking the appropriate dilution into wastewater treatment plant effluent to reach one of the five lower target concentration levels.
Preparation of Passive Dosing Systems. Silicone rods were cleaned (see Supporting Information S1) and then cut into five pieces of $20.00 \mathrm{~g}$ and rolled up into $100 \mathrm{~mL}$ amber glass serum bottles. ${ }^{32}$ It was chosen to load solid test chemicals close to their solubility limit. Predictions of partitioning between silicone and water ${ }^{34}$ were used for initial estimates of loading levels, which were then tested in a small pre-test of the loading levels and compared to standards in order to set the final procedure for loading of the silicone rods.

Solid chemicals were loaded into the silicone rods by equilibrium partitioning from a methanol solution. The methanol solution containing the solid chemicals was prepared by adding $10 \mathrm{~g}$ of tonalide, musk ketone, drometrizole, dicyclohexyl phthalate, phenanthrene, $3 \mathrm{~g}$ of anthraquinone, 2 $\mathrm{g}$ of tert-butyl-4-methoxyphenol, and $0.5 \mathrm{~g}$ of naphthalene and 1,3,5-trichlorobenzene to $500 \mathrm{~mL}$ of methanol. Though the methanol solubility was only known for a few of the chemicals, residual crystals indicated that for some chemicals this solution was saturated (most likely phenanthrene and musk ketone), whereas for some it was not (e.g., naphthalene). This solution was sonicated two times for $15 \mathrm{~min}$ and left to settle overnight. $64 \mathrm{~g}$ of the supernatant of this solution (measured by weight) was then added to each passive dosing system. They were then rolled overnight for equilibrium loading from the methanol solution. The rods were then rinsed with ultrapure water. This rinse caused some formation of crystals on the silicone rods. The rods were therefore wiped carefully twice with lint-free tissues slightly wetted in methanol to mechanically remove the crystals from their surface and placed in new $100 \mathrm{~mL}$ amber serum bottles.

Liquid chemicals were subsequently loaded into the same silicone rods via the absorption of an added liquid mix. A mixture of most of the liquid test chemicals was prepared by mixing $100 \mu \mathrm{L}$ of citronellol, linalool, geraniol, $\alpha$-isomethylionone, dibutyl phthalate, oxacycloheptadec-10-en-2-one, and 4tert-butylcyclohexyl acetate with $500 \mu \mathrm{L}$ of 2-ethylhexyl 4methoxycinnamate and 2-ethylhexyl salicylate. $170 \mu \mathrm{L}$ of this mixture and $10 \mu \mathrm{L}$ of homosalate was then added to each of the five silicone rods and rolled overnight for absorption of the liquid test chemicals. The silicone was then rinsed three times with ultrapure water.

Preparation of Test Systems. Each experiment consisted of 21 abiotic test systems, 21 biotic test systems, and 7 blanks prepared in $20 \mathrm{~mL}$ amber precision thread headspace vials 
(Mikrolab Aarhus) closed with gastight magnetic screw caps with PTFE/silicone septa (Sigma-Aldrich). This test system format ensured alignment with the analytical method. The highest concentrations (level 1) were prepared by equilibrating the WWTP effluent with the loaded silicone rods for $2 \mathrm{~h}$ (80 $\mathrm{mL}$ in each of four passive dosing system) and transferring 15 $\mathrm{mL}$ of this solution to each test system (the dimensions of the passive dosing systems ensure fast equilibration kinetics, ${ }^{30,32}$ which were also confirmed by measurements of initial concentrations: Figures 1 and S1 and Table S1). The other concentrations levels $(2-6)$ were prepared by equilibrating 80 $\mathrm{mL}$ of ultrapure water with the loaded silicone rods in a passive dosing system (rolling overnight at $30 \mathrm{rpm}$ and room temperature) and diluting this solution 1:10, 1:100, 1:1000, $1: 10,000$, and 1:100,000 into the WWTP effluent. Abiotic test systems were prepared at the same test chemical concentrations using ultrapure water instead of wastewater treatment plant effluent. In an earlier study, ${ }^{37}$ using river water with a low content of suspended solids and organic matter as inoculum, this method for preparing abiotic controls has been shown to produce similar results as when using sodium azide for poisoned abiotic controls. In order to limit the use of toxic chemicals it was deemed sufficient here.

All test systems were incubated at $12{ }^{\circ} \mathrm{C}$ in the dark on benchtop rollers at approximately $30 \mathrm{rpm}$. At varying time points from 1 to 30 days, three abiotic and three biotic test systems were then moved to the autosampler and analyzed alternating biotic and abiotic test systems. One analysis lasted 1.5 hours, and it was ensured that all samples were analyzed within $24 \mathrm{~h}$ on the autosampler at room temperature $(88 \%$ were analyzed within $16 \mathrm{~h}$ ). The highest three concentration levels $(1-3)$ were diluted $1: 10,1: 100$ or $1: 1000$ in new headspace vials before analysis.

DNA Extractions. Due to the low microbial load of the effluent, DNA extractions required a volume of $80 \mathrm{~mL}$ and therefore separate test systems were prepared for this purpose. Triplicate test systems at the highest concentration (level 1) were prepared by adding $80 \mathrm{~mL}$ of inoculum equilibrated with the loaded silicone rods to $100 \mathrm{~mL}$ amber serum bottles with crimp caps. Triplicate medium concentration test systems (level 3) and low concentration test systems (level 5) were prepared by diluting passive dosed water $1: 100$ or $1: 10,000$ with inoculum. Three test systems containing only $80 \mathrm{~mL}$ of inoculum (not spiked) were also prepared. These test systems were incubated with the smaller test systems at $12{ }^{\circ} \mathrm{C}$ for 14 days. The incubation time of 14 days was chosen in order to exceed the lag time for most chemicals and see the development in the microbial composition during degradation whereas avoiding starvation of microbes to affect the composition too much.

At the day of test setup (day 0$)$, two blank samples $(80 \mathrm{~mL}$ of ultrapure water) and three inoculum samples $(80 \mathrm{~mL}$ of WWTP effluent) were filtered through Millipore $0.2 \mu \mathrm{m}$ filter paper using suction filtering. On day 14, the content of the 12 incubated large test systems were likewise filtered. The filter papers were then stored at $-80{ }^{\circ} \mathrm{C}$ and sent for DNA extraction and 16S rRNA gene amplicon sequencing by DNASense (Aalborg, Denmark). The DNeasy PowerWater kit (Qiagen, Germany) was used for extraction. A custom protocol based on the Illumina protocol was used for library preparation and sequencing, using V3 chemistry. The following primer set was used to target the archaeal and bacterial $16 \mathrm{~S}$ rRNA gene
V1-3 region: [27F] AGAGTTTGATCCTGGCTCAG and [534R] ATTACCGCGGCTGCTGG. ${ }^{38}$

Chemical Analysis. Automated sorptive enrichment was done directly on the unopened test systems using immersion Arrow-SPME ${ }^{26}$ operated by a PAL RTC 120 autosampler (CTC, Zwingen, Switzerland). The Arrow-SPME fiber was then thermally desorbed in the injector of a 7890B GC system with a MS/MS detector (7010B GC/TQ) (Agilent Technologies, Denmark).

Test systems were first heated for $10 \mathrm{~min}$ at $35{ }^{\circ} \mathrm{C}$. Then, chemicals were enriched with a $250 \mu \mathrm{m}$ Arrow-SPME fiber immersed in the liquid for $60 \mathrm{~min}$ at $35^{\circ} \mathrm{C}$ with continuous agitation $(300 \mathrm{rpm})$. Desorption was done in the $\mathrm{GC}$ inlet at $280{ }^{\circ} \mathrm{C}$ for $10 \mathrm{~min}$. Pre- and post-conditioning of the ArrowSPME was $5 \mathrm{~min}$ at $280{ }^{\circ} \mathrm{C}$. Separation was obtained on a 60 $\mathrm{m} \times 250 \mu \mathrm{m} \times 0.25 \mu \mathrm{m}$ DB-5 ms Ultra Inert column (Agilent) using helium as a carrier gas at $1.2 \mathrm{~mL} / \mathrm{min}$. The oven temperature was ramped from $50{ }^{\circ} \mathrm{C}$ to $310{ }^{\circ} \mathrm{C}$ at $10{ }^{\circ} \mathrm{C} / \mathrm{min}$ with a hold of $5 \mathrm{~min}$. Detection was done on a triple quadrupole detector (MS/MS) in multiple reaction monitoring mode (MRM) using two sets of transitions from the precursor to product ion for each test chemical. Collision energies were optimized for each transition and ranged from 0 to $40 \mathrm{eV}$.

WWTP effluent concentrations and initial concentrations in the test system at the test start were determined using external standards.

Data Analysis. Based on the chromatography of the wastewater treatment plant effluent, a peak area cutoff was set for each chemical to represent approximately three times the baseline fluctuations (or blank response, if any). Below this cutoff, the peaks in biotic test systems were integrated as best as possible at the exact retention time, and data points were indicated by open symbols in degradation plots. Any data points where the abiotic controls were below this cutoff were excluded. Four chemicals were completely excluded: 2ethylhexyl salicylate, oxacycloheptadec-10-en-2-one, and homosalate had too low signals in abiotic controls, and dibutyl phthalate had contamination of blanks.

Test systems were analyzed alternating biotic and abiotic test systems. Biodegradation kinetics were determined by pairing the biotic test system and subsequent abiotic control, and determining the ratio between their signal responses $\left(R_{\text {biotic/abiotic }}\right)$. This ratio thus corrects for abiotic losses and instrument sensitivity variations over the 28 days of the biodegradation test.

Carryover was evaluated as the ratio between measurements of the highest standard and a subsequent blank sample. Any $R_{\text {biotic/abiotic }}$ below average carryover signal plus 3 times the standard deviation on carryover signal was set to this carryover limit. The carryover limits varied from 0.02 to $1.1 \%$ for all chemicals except homosalate, anthraquinone, and drometrizole with average carryovers of 1,1 , and $2 \%$ and carryover limits of $2.5,5$, and $7 \%$.

After the main degradation phase, concentrations in the biotic vials will be low and measurement precision decreases. We thus focused the fitting to the initial and main degradation phase, by limiting the fitting to two data points below an $R_{\text {biotic/abiotic }}$ of 0.01 .

A first-order degradation model with lag phase, $t_{\text {lag }}$, was fitted to these $R_{\text {biotic/abiotic }}$ (eq 2) using GraphPad Prism 9.0.0. $k$ is the first-order degradation rate constant, $t$ is the incubation time, and $t_{1 / 2}$ is the first-order half-life $(\ln (2) / k)$. Degradation half- 

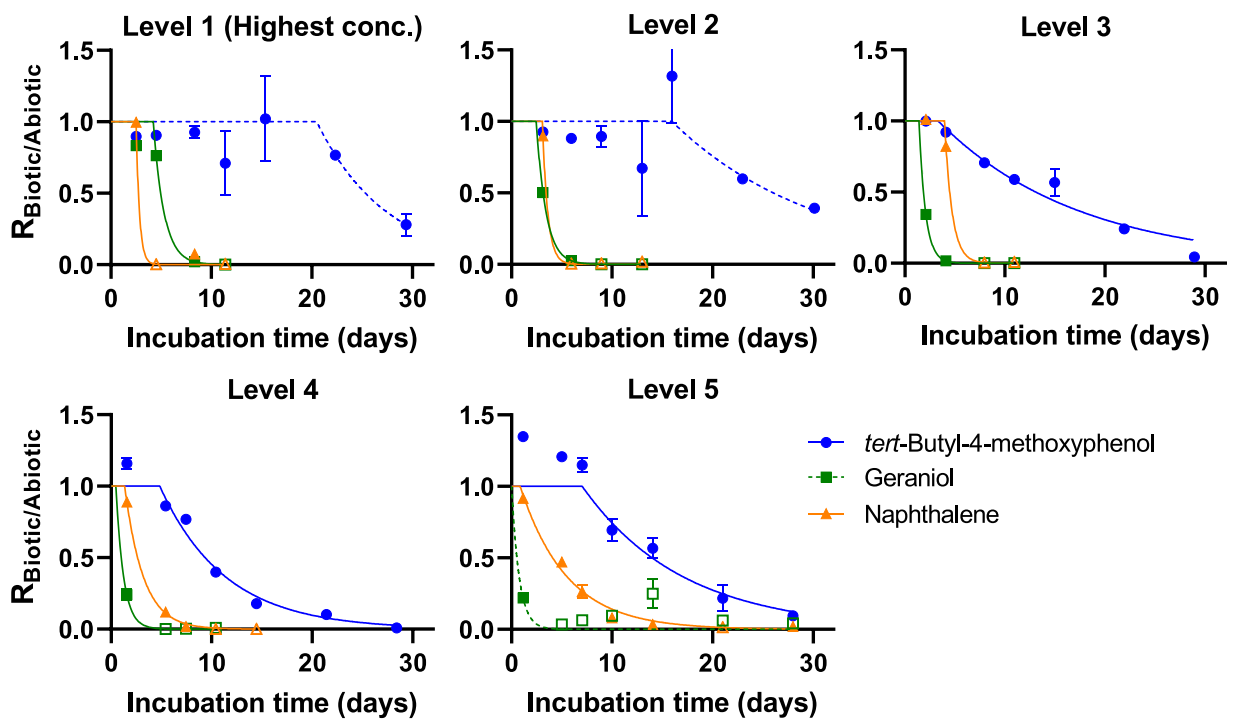

Figure 2. First-order biodegradation kinetics of tert-butyl-4-methoxyphenol, geraniol, and naphthalene at five concentration levels. Biodegradation curves with $R^{2}<0.7$ are indicated with broken lines. Open symbols indicate that biotic test systems were below detection limits. Error bars show standard error on mean (SEM), $n=3$.

times, $\operatorname{Deg} T_{50}$, were calculated as the sum of the first-order half-life and the lag phase.

$$
R_{\text {biotic } / \text { abiotic }}= \begin{cases}1 & \text { for } t<t_{\text {lag }} \\ \mathrm{e}^{-k\left(t-t_{\mathrm{lag}}\right)} & \text { for } t>t_{\mathrm{lag}}\end{cases}
$$

DNA Sequence Analysis. The reads were trimmed using Trimmomatic v. $0.32^{39}$ with the settings SLIDING WINDOW: 5:3 and MINLEN: 225 and merged using FLASH v. $1.2 .7^{40}$ with the settings $-\mathrm{m} 10$ and $-\mathrm{M}$ 250. The merged, dereplicated reads were then clustered, using the USEARCH v.7.0.1090-cluster_otus command (default settings). Operational taxonomic unit (OTU) abundances were estimated using the USEARCH v. 7.0.1090-USEARCH_global command with -id 0.97 -maxaccepts 0 -maxrejects 0 . The RDP classifier ${ }^{41}$ was used to assign taxonomy as implemented in the parallel_assign_taxonomy_rdp.py script in QIIME, ${ }^{42}$ using -confidence $0 . \overline{8}$ and the SILVA database, release $132 .{ }^{43}$ The results were analyzed in $\mathrm{R}$ v. 4.0.2 through the RStudio IDE using the ampvis package v.2.6.4. ${ }^{44}$ The Hellinger transformation $^{45}$ was applied on OTU abundance data before ordination by principal components analysis (PCA). The raw sequencing reads are available on GenBank under study number PRJNA730809.

\section{RESULTS AND DISCUSSION}

WWTP Effluent and Initial Test Concentrations. Nonspiked WWTP effluent concentrations, initial test system concentrations, and the literature data for solubility of six test chemicals are shown in Figure 1 (additional data can be found in S2). All test concentrations were below water solubility for all chemicals [solubilities obtained from the Danish (Q)SAR database $\left.{ }^{46}\right]$. The three chemicals with level 1 concentrations closest to their solubility were phenanthrene ( 0.57 times solubility), tonalide ( 0.24 times solubility), and musk ketone ( 0.15 times solubility). For phenanthrene, this was $21 \%$ of its subcooled liquid solubility ${ }^{47}$ and thus near the concentrations range for baseline toxicity. ${ }^{48,49}$ The other test chemicals had level 1 concentrations 1 to 4 orders of magnitude below the literature data for their water solubility. WWTP effluent concentrations interfered with the lower test concentrations for some of the chemicals (Figure 1), most distinctly for tonalide and homosalate (Figure 1B), where biodegradation was not evaluated for the lower three concentration levels.

Reference Chemicals. 1,3,5-Trichlorobenzene was included in the study as a poorly degradable chemical. No sign of biodegradation was seen for 1,3,5-trichlorobenzene at levels $1-3$. Levels 4 and 5 were termed "inconclusive" because of one data point with $R_{\text {biotic/abiotic }}<0.5$ and no trend in data points, whereas MS signal was too low at level 6. Anthraquinone was included as an inherently degradable chemical. In this study, anthraquinone was not degraded with no data points below 0.5 at any concentration levels. Naphthalene and phenanthrene were included as chemicals that degraded in most cases in our earlier studies. ${ }^{6,30}$ Naphthalene and phenanthrene were degraded at all concentration levels (Figure 2 and S3). No baseline toxicity or slower degradation were seen for phenanthrene at the highest concentration level even though concentrations were close to its water solubility. Degradation half-times for naphthalene (2.6-7.6 days) were in the range of those found in earlier degradation experiments using stream water as inoculum (3.1-6.5 days). ${ }^{27,30}$ The stream water used in those studies had bacterial plate counts similar to the plate counts found in the WWTP effluent used as inoculum here (Table S1). Degradation half-times for naphthalene and phenanthrene in the present study were longer than in an earlier study using activated sludge filtrate that had higher bacterial plate counts. They were, however, shorter than halftimes in seawater and lake water that had lower bacterial plate counts. ${ }^{6}$ This inoculum was deemed to be biologically active based on the degradation of naphthalene and phenanthrene in line with earlier studies, but was not diverse and active enough for anthraquinone to be degraded.

Biodegradation of Test Chemicals. The fit of a firstorder biodegradation kinetic model to the biodegradation data for three selected chemicals is shown in Figure 2. Biodegradation plots including data points for all nine chemicals can be found in Supporting Information S4. 


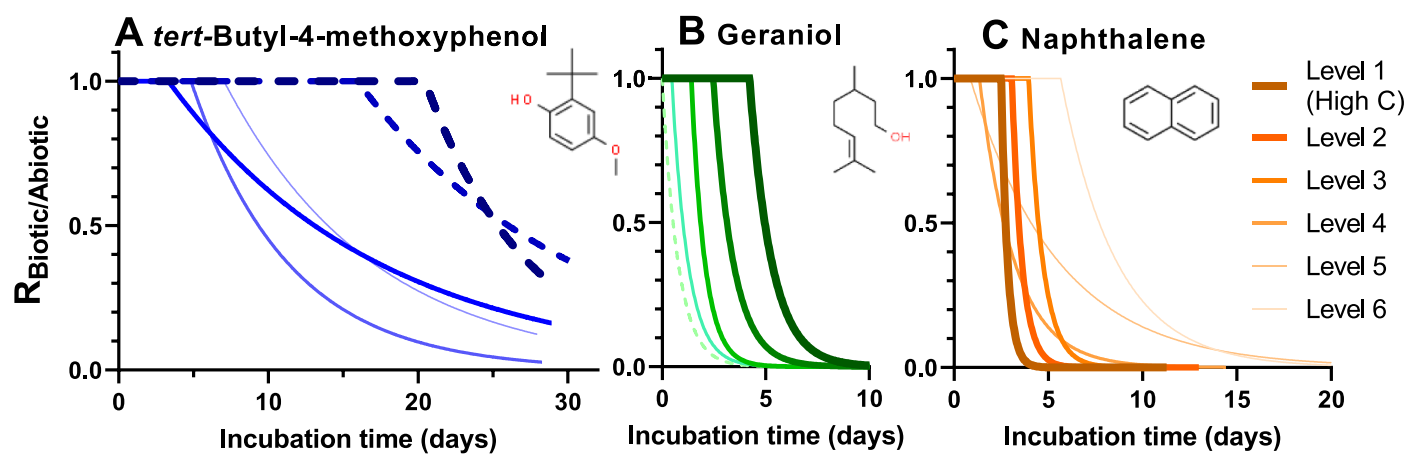

Figure 3. First-order biodegradation kinetics of tert-butyl-4-methoxyphenol (A), geraniol (B), and naphthalene (C) at 5-6 concentration levels spaced a factor 10 apart-highest concentration $=$ darkest and boldest line. Biodegradation curves with $R^{2}<0.7$ are indicated with broken lines.
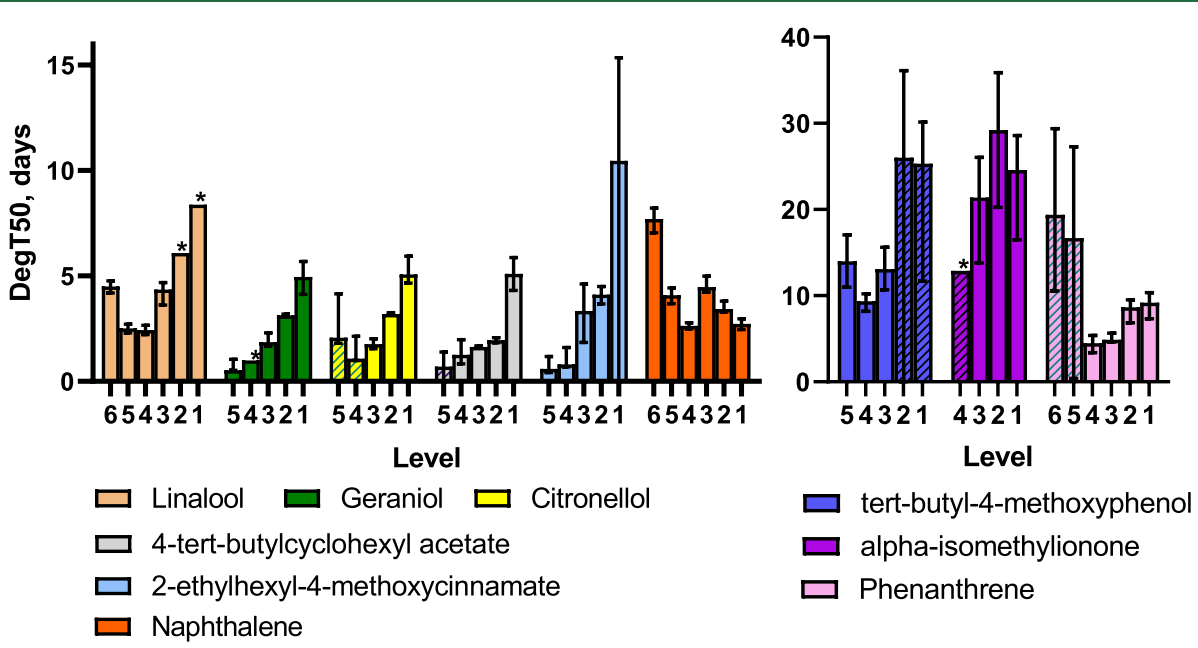

Figure 4. Biodegradation half-times, $\operatorname{Deg} T_{50}$, for nine chemicals as a function of concentration level. There is a factor of 10 between the concentration in each level, and level 6 is the lowest concentration. Error bars were calculated as DegT $T_{50} \pm 95 \%$ confidence limits on $t_{1 / 2}$. ${ }^{*}$ No error bars because fit was "ambiguous". Deg $T_{50}$ found from biodegradation curves with $R^{2}<0.7$ are hatched.

For the three chemicals, linalool, geraniol, and citronellol, some ratios during the lag phase were $0.85-0.9$ instead of 1.0 (Figure S2). The three chemicals showed the fastest degradation among the test chemicals, and the data resolution was thus not high enough to conclude on a possible two-phase degradation.

No degradation kinetic data could be derived for musk ketone, drometrizole, and tonalide as a maximum of one data point was below 0.5 and very limited degradation was thus seen. Dicyclohexyl phthalate was fully degraded at the highest concentration, partly degraded at the second highest concentration, but not degraded at the lower concentrations (Supporting Information S4).

Concentration Effect on Biodegradation Kinetics. The concentration effect on biodegradation kinetics is here evaluated for the nine chemicals where substantial degradation was seen at three or more concentration levels and is illustrated for three chemicals in Figure 3.

Most of the chemicals that fully degraded had longer biodegradation half-times with higher test concentrations (Figures 4 and S2). In many cases, this was mainly caused by increasing lag phases with higher concentrations and similar degradation rate constants (Figures 2A,B, S2, and S3) (linalool, geraniol, citronellol, 4-tert-butylcyclohexyl acetate, 2-ethylhexyl-4-methoxycinnamate, and tert-butyl-4-methoxyphenol). 95\% confidence limits on the half-lives (Table S2) showed that for linalool, the half-lives at the two lowest concentration levels were higher than at the two middle concentration levels (no overlap of confidence intervals), for naphthalene the half-lives of the three lowest concentration levels were longer than the half-lives at the three highest concentration levels, and for $\alpha$-isomethylionone the half-life at the highest concentration was shorter than at the second highest concentration. Other than for these three chemicals, the confidence limits did not show statistically different halflives between the tested concentration levels. The pattern of the increasing lag phases showed that the inoculum was (almost) ready for degradation at low concentrations, whereas some adaptation, growth, or enzyme production was needed at the highest concentrations. The reference chemicals naphthalene and phenanthrene had a different pattern of biodegradation kinetics. They had the longest biodegradation half-times at the lowest test concentrations (6 and $11 \mathrm{ng} / \mathrm{L}$, respectively) (Figures $3 \mathrm{C}$ and 4 ), stemming from longer lag phases before biodegradation occurred and slightly longer halflives (Figures 2A, S2, and S3).

Microbial Community Changes. The concentration of DNA decreased from $0.22 \mathrm{ng} / \mathrm{L}$ in the initial WWTP effluent to $0.029-0.099 \mathrm{ng} / \mathrm{L}$ in the non-spiked test system, level 3 (medium conc.), and level 5 (low conc.) test systems after 14 days of incubation. In contrast, it remained more stable or even increased in level 1 (high concentration) test systems (0.18$0.48 \mathrm{ng} / \mathrm{L})$. This decline in DNA concentration to $22-29 \%$ of the initial value in all incubations except at the highest 
concentration level was most likely caused by starvation and decay of the microbes, after the exhaustion of organic substrates. Indeed, the dissolved non-volatile organic carbon content of the effluent was $10.1 \mathrm{mg} \mathrm{C} / \mathrm{L}$, of which only a fraction would be assimilable. The spiked chemical at levels 3 and 5 provided a very limited additional organic carbon $(0.2$ and $0.002 \mathrm{mg} \mathrm{C} / \mathrm{L}$, respectively). This was not the case with the $17 \mathrm{mg} \mathrm{C} / \mathrm{L}$ spiked at level 1 , which can significantly support microbial metabolism and growth. The biodegradation data (Figures 4 and S2) indeed indicate that by the sampling date (14 days), the most easily degradable chemicals were fully degraded (linalool, citronellol, geraniol, 4-tert-butylcyclohexyl acetate, naphthalene, and phenanthrene at medium-to-high concentrations), suggesting that a large fraction $(>80 \%)$ of the total spiked organic carbon had been consumed.

The 25 most abundant genera among the samples are shown in Supporting Information S5. The most abundant genus in the effluent sample was Arcobacter (about $15 \%$ in relative abundance). After 14 days of incubation, the microbial composition deviated clearly from the original inoculum for all treatments, as illustrated by the PCA (Figure 5). The

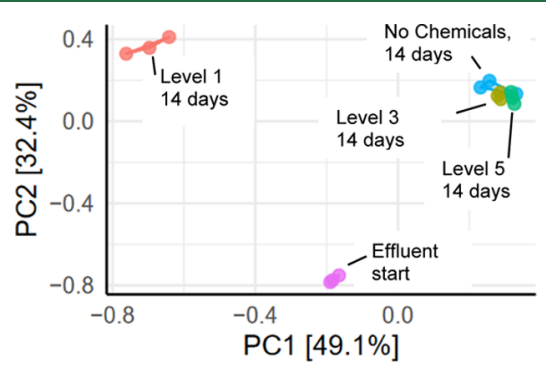

Figure 5. PCA of 15 samples including 390 OTUs. The data has been transformed initially by applying the Hellinger transformation. ${ }^{45}$ The relative contribution (eigenvalue) of each axis to the total inertia in the data is indicated in percent at the axis titles.

microbial community in the test systems without chemical addition (no chemicals), level 3 (medium conc.), and level 5 (low conc.) developed similarly with Candidatus Nitrotoga as the most abundant genera. The microbial population in level 1 (high conc.) developed very differently with the rise to dominance of genera Acidovorax, Novosphingobium, and Hydrogenophaga (collectively accounting for about half of the reads vs $<2 \%$ in all other samples). The proliferation of these OTUs, presumably because they metabolized the spiked chemicals, resulted in a drop in diversity, the OTU richness falling to 390 and 530, compared to 1200 and 1600 for all other samples. These three genera have often been observed to degrade aromatic compounds (e.g., Acidovorax: chlorobenzenes $^{50}$ and polychlorobiphenyl; ${ }^{51}$ Novosphingobium: aromatic compounds and PAHs; ${ }^{52-54}$ Hydrogenophaga: 4-aminobenzenesulfonate $^{55}$ and PAHs. ${ }^{56}$ ).

Overall, the microbial community analysis thus revealed that the growth of a few genera of specific degraders occurred at the highest concentration levels. This is in line with the findings of Simkins and Alexander ${ }^{17}$ who reported the Monod growth kinetics to start at around $1 \mathrm{mg} / \mathrm{L}$. Below this level, chemicals were still degraded, but the influence of the chemicals on the microbial community was minimal. The lag phases observed at the low concentration levels could then be explained by the time needed for the activation and expression of the relevant enzymes in the diverse microbial community rather than by the growth of the specific degraders.

Implications for Biodegradation Testing. Biodegradation kinetics (half-lives) are used in multimedia fate models and are a key basis for persistence assessment in regulatory frameworks, with an implicit assumption that persistence criteria refer to degradation in the field. ${ }^{1}$ However, the measured biodegradation depends on the imposed experimental conditions. ${ }^{1,37}$ As seen here, tests performed at high concentrations can reveal whether the chemicals can support the growth of specific degraders. However, the biodegradation kinetics used for fate modeling and persistence assessment should preferably simulate environmental conditions as closely as possible where other carbon sources than the contaminants are likely most abundant and lower test chemical concentrations should, therefore, be used. This study supports and illustrates that it is possible to perform biodegradation testing at low concentrations and in mixtures. The fact that some of the chemicals were found in the wastewater treatment plant effluent at concentrations similar or above the lowest concentration levels planned, illustrates that these concentration levels are in fact environmentally relevant. Although low test concentrations should be used, constraints on test concentrations include the sensitivity of analysis and background concentrations in the inocula used, which will inevitably be lower for surface waters than for WWTP effluent.

This study did not reveal a general concentration threshold below which biodegradation did not occur and the direction of the concentration effect depended on the chemical. Most chemicals degraded faster at lower concentrations (mainly lag phase was affected), but some degraded slower, and dicyclohexyl phthalate did not degrade at the low concentrations but did at the highest concentration. Apparently, this chemical needed adaptation, the growth of specific degraders, or the production of specific enzymes in order to be degraded, which only happened at the highest concentrations, 9 and 80 $\mu \mathrm{g} / \mathrm{L}$, but not at $6-100 \mathrm{ng} / \mathrm{L}$ concentrations. There may thus for some chemicals exist a threshold in the low $\mu \mathrm{g} / \mathrm{L}$ range below which they are not degraded, whereas for most chemicals this was not seen.

During the first 14 days of incubation, the microbial abundance decreased markedly at the low and medium concentration levels. This was probably caused by a starvation of the microbes. Carbon-limiting conditions have been seen to stimulate the biodegradation of phenol. ${ }^{57}$ It may therefore influence the degradation of chemicals. Although the present study cannot conclude whether this was the case, the method presented here could be used to investigate such matters in further studies.

Conducting a biodegradation test on a mixture of chemicals can provide degradation kinetic data that are better aligned between chemicals and that are also highly relevant for surface waters that receive WWTP discharges containing a mixture of xenobiotics. The present study provides new evidence that (1) the mixture concentration can affect the biodegradation kinetics of the mixture constituents, (2) this mixture effect can vary with the constituent and thus lead to a change in which order chemicals degrade, and (3) the mixture concentration also affects the microbial composition of the degrader community in the test. However, the present study did not reveal which chemicals were the main drivers for the observed mixture effects, which in turn warrants more research on the mixture effects on biodegradation kinetics. 


\section{ASSOCIATED CONTENT}

\section{s) Supporting Information}

The Supporting Information is available free of charge at https://pubs.acs.org/doi/10.1021/acs.est.1c05583.

Cleaning method for silicone rods, initial test system concentrations, biodegradation kinetic curves and data, and community composition (PDF)

\section{AUTHOR INFORMATION}

\section{Corresponding Author}

Heidi Birch - Department of Environmental Engineering,

Technical University of Denmark, 2800 Kgs. Lyngby,

Denmark; 이이이.org/0000-0002-7152-3832;

Phone: +45 45251417; Email: hbir@env.dtu.dk

\section{Authors}

Karina Knudsmark Sjøholm - Department of Environmental Engineering, Technical University of Denmark, $2800 \mathrm{Kgs}$. Lyngby, Denmark; Present Address: Haldor Topsøe, Haldor Topsøes Allé 1, 2800, Kgs. Lyngby, Denmark; (1) orcid.org/0000-0002-2964-3849

Arnaud Dechesne - Department of Environmental Engineering, Technical University of Denmark, $2800 \mathrm{Kgs}$. Lyngby, Denmark; (1) orcid.org/0000-0002-6638-2158

Chris Sparham - Safety \& Environmental Assurance Centre, Unilever, Bedford MK44 1LQ U.K.

Roger van Egmond - Safety \& Environmental Assurance Centre, Unilever, Bedford MK44 1LQ U.K.

Philipp Mayer - Department of Environmental Engineering, Technical University of Denmark, 2800 Kgs. Lyngby,

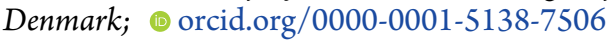

Complete contact information is available at: https://pubs.acs.org/10.1021/acs.est.1c05583

\section{Notes}

The authors declare no competing financial interest.

\section{ACKNOWLEDGMENTS}

The authors thank Unilever for financial support and CTC for support and collaboration. We also thank Alexandre Teixeira and Geoff Hodges for discussions and comments and Hanne Bøggild, Sinh Hy Nguyen, and Lene Kirstejn Jensen for technical assistance in the laboratory. Furthermore, we thank Global Product Compliance Europe $\mathrm{AB}$ for providing test substances and BIOFOS Spildevandscenter Avedøre A/S for providing effluent samples.

\section{REFERENCES}

(1) Boethling, R.; Fenner, K.; Howard, P.; Klečka, G.; Madsen, T.; Snape, J. R.; Whelan, M. J. Environmental Persistence of Organic Pollutants: Guidance for Development and Review of POP Risk Profiles. Integr. Environ. Assess. Manage. 2009, 5, 539-556.

(2) OECD Guideline for Testing of Chemicals. Ready Biodegradability, 1992; pp 1-62. OECD 301.

(3) OECD Guidelines for the Testing of Chemicals. Biodegradability in Seawater, 1992; pp 1-27. OECD 306.

(4) OECD Guideline for the Testing of Chemicals. Aerobic Mineralisation in Surface Water-Simulation Biodegradation Test; OECD, 2004. OECD 309.

(5) Seller, C.; Honti, M.; Singer, H.; Fenner, K. Biotransformation of Chemicals in Water-Sediment Suspensions: Influencing Factors and Implications for Persistence Assessment. Environ. Sci. Technol. Lett. 2020, 7, 854 .
(6) Birch, H.; Hammershøj, R.; Mayer, P. Determining Biodegradation Kinetics of Hydrocarbons at Low Concentrations: Covering 5 and 9 Orders of Magnitude of Kow and Kaw. Environ. Sci. Technol. 2018, 52, 2143-2151.

(7) Fenner, K.; Screpanti, C.; Renold, P.; Rouchdi, M.; Vogler, B.; Rich, S. Comparison of Small Molecule Biotransformation Half-Lives between Activated Sludge and Soil: Opportunities for Read-Across? Environ. Sci. Technol. 2020, 54, 3148-3158.

(8) Boethling, R. S.; Alexander, M. Effect of Concentration of Organic Chemicals on Their Biodegradation by Natural Microbial Communities. Appl. Environ. Microbiol. 1979, 37, 1211-1216.

(9) Ingerslev, F.; Baun, A.; Nyholm, N. Aquatic Biodegradation Behavior of Pentachlorophenol Assessed through a Battery of Shake Flask Die-Away Tests. Environ. Toxicol. Chem. 1998, 17, 1712-1719.

(10) Southwell, R. V.; Hilton, S. L.; Pearson, J. M.; Hand, L. H.; Bending, G. D. Inclusion of Seasonal Variation in River System Microbial Communities and Phototroph Activity Increases Environmental Relevance of Laboratory Chemical Persistence Tests. Sci. Total Environ. 2020, 733, 139070.

(11) Honti, M.; Bischoff, F.; Moser, A.; Stamm, C.; Baranya, S.; Fenner, K. Relating Degradation of Pharmaceutical Active Ingredients in a Stream Network to Degradation in Water-Sediment Simulation Tests. Water Resour. Res. 2018, 54, 9207-9223.

(12) Ahtiainen, J.; Aalto, M.; Pessala, P. Biodegradation of Chemicals in a Standardized Test and in Environmental Conditions. Chemosphere 2003, 51, 529-537.

(13) Wirsching, J.; Pagel, H.; Ditterich, F.; Uksa, M.; Werneburg, M.; Zwiener, C.; Berner, D.; Kandeler, E.; Poll, C. Biodegradation of Pesticides at the Limit: Kinetics and Microbial Substrate Use at Low Concentrations. Front. Microbiol. 2020, 11, 2107.

(14) Li, Z.; McLachlan, M. S. Biodegradation of Chemicals in Unspiked Surface Waters Downstream of Wastewater Treatment Plants. Environ. Sci. Technol. 2019, 53, 1884-1892.

(15) Martin, T. J.; Snape, J. R.; Bartram, A.; Robson, A.; Acharya, K.; Davenport, R. J. Environmentally Relevant Inoculum Concentrations Improve the Reliability of Persistent Assessments in Biodegradation Screening Tests. Environ. Sci. Technol. 2017, 51, 3065-3073.

(16) Monod, J. The Growth of Bacterial Cultures. Annu. Rev. Microbiol. 1949, 3, 371-394.

(17) Simkins, S.; Alexander, M. Models for Mineralization Kinetics with the Variables of Substrate Concentration and Population Density. Appl. Environ. Microbiol. 1984, 47, 1299-1306.

(18) Johnson, K. A.; Goody, R. S. The Original Michaelis Constant: Translation of the 1913 Michaelis-Menten Paper. Biochemistry 2011, 50, 8264-8269.

(19) Edwards, V. H. The Influence of High Substrate Concentrations on Microbial Kinetics. Biotechnol. Bioeng. 1970, 12, 679-712. (20) Gharasoo, M.; Centler, F.; Van Cappellen, P.; Wick, L. Y.; Thullner, M. Kinetics of Substrate Biodegradation under the Cumulative Effects of Bioavailability and Self-Inhibition. Environ. Sci. Technol. 2015, 49, 5529-5537.

(21) van Bergen, T. J. H. M.; Rios-Miguel, A. B.; Nolte, T. M.; Ragas, A. M. J.; van Zelm, R.; Graumans, M.; Scheepers, P. T. J.; Jetten, M. S. M.; Hendriks, A. J.; Welte, C. U. Do Initial Concentration and Activated Sludge Seasonality Affect Pharmaceutical Biotransformation Rate Constants? Appl. Microbiol. Biotechnol. 2021, 105, 6515-6527.

(22) Toräng, L.; Nyholm, N.; Albrechtsen, H.-J. Shifts in Biodegradation Kinetics of the Herbicides MCPP and 2,4-D at Low Concentrations in Aerobic Aquifer Materials. Environ. Sci. Technol. 2003, 37, 3095-3103.

(23) Smith, K. E. C.; Rein, A.; Trapp, S.; Mayer, P.; Karlson, U. G. Dynamic Passive Dosing for Studying the Biotransformation of Hydrophobic Organic Chemicals: Microbial Degradation as an Example. Environ. Sci. Technol. 2012, 46, 4852-4860.

(24) Hammershøj, R.; Birch, H.; Redman, A. D.; Mayer, P. Mixture Effects on Biodegradation Kinetics of Hydrocarbons in Surface Water: Increasing Concentrations Inhibited Degradation Whereas Multiple Substrates Did Not. Environ. Sci. Technol. 2019, 53, 3087-3094. 
(25) Egli, T. How to Live at Very Low Substrate Concentration. Water Res. 2010, 44, 4826-4837.

(26) Kremser, A.; Jochmann, M. A.; Schmidt, T. C. PAL SPME Arrow - Evaluation of a Novel Solid-Phase Microextraction Device for Freely Dissolved PAHs in Water. Anal. Bioanal. Chem. 2016, 408, 943-952.

(27) Birch, H.; Andersen, H. R.; Comber, M.; Mayer, P. Biodegradation Testing of Chemicals with High Henry's Constants - Separating Mass and Effective Concentration Reveals Higher Rate Constants. Chemosphere 2017, 174, 716-721.

(28) Kowalczyk, A.; Martin, T. J.; Price, O. R.; Snape, J. R.; van Egmond, R. A.; Finnegan, C. J.; Schäfer, H.; Davenport, R. J.; Bending, G. D. Refinement of Biodegradation Tests Methodologies and the Proposed Utility of New Microbial Ecology Techniques. Ecotoxicol. Environ. Saf. 2015, 111, 9-22.

(29) Comber, M.; Holt, M. Developing a Set of Reference Chemicals for Use in Biodegradability Tests for Assessing the Persistency of Chemicals. MCC Report, 2010, MCC/007.

(30) Birch, H.; Hammershøj, R.; Comber, M.; Mayer, P. Biodegradation of Hydrocarbon Mixtures in Surface Waters at Environmentally Relevant Levels - Effect of Inoculum Origin on Kinetics and Sequence of Degradation. Chemosphere 2017, 184, 400407.

(31) Hammershøj, R.; Sjøholm, K. K.; Birch, H.; Brandt, K. K.; Mayer, P. Biodegradation Kinetics Testing of Two Hydrophobic UVCBs - Potential for Substrate Toxicity Supports Testing at Low Concentrations. Environ. Sci.: Processes Impacts 2020, 22, 2172-2180.

(32) Hammershøj, R.; Birch, H.; Sjøholm, K. K.; Mayer, P. Accelerated Passive Dosing of Hydrophobic Complex Mixtures Controlling the Level and Composition in Aquatic Tests. Environ. Sci. Technol. 2020, 54, 4974-4983.

(33) Smith, K. E. C.; Dom, N.; Blust, R.; Mayer, P. Controlling and Maintaining Exposure of Hydrophobic Organic Compounds in Aquatic Toxicity Tests by Passive Dosing. Aquat. Toxicol. 2010, 98, $15-24$.

(34) Ulrich, N.; Endo, S.; Brown, T. N.; Watanabe, N.; Bronner, G.; Abraham, M. H.; Goss, K.-U. UFZ-LSER Database V 3.2.1 https:// www.ufz.de $/$ index.php? en $=31698 \&$ contentonly $=1 \& \mathrm{~m}=0 \& 1$ serd data $[\mathrm{mvc}]=$ Public/start.

(35) Biofos. Miljøberetning for 2019 (Environmental Report 2019), in Danish, 2019.

(36) Mansfeldt, C.; Deiner, K.; Mächler, E.; Fenner, K.; Eggen, R. I. L.; Stamm, C.; Schönenberger, U.; Walser, J.-C.; Altermatt, F. Microbial Community Shifts in Streams Receiving Treated Wastewater Effluent. Sci. Total Environ. 2020, 709, 135727.

(37) Sjøholm, K. K.; Birch, H.; Hammershøj, R.; Saunders, D. M. V.; Dechesne, A.; Loibner, A. P.; Mayer, P. Determining the Temperature Dependency of Biodegradation Kinetics for 34 Hydrocarbons While Avoiding Chemical and Microbial Confounding Factors. Environ. Sci. Technol. 2021, 55, 11091-11101.

(38) Ward, D. V.; Grevers, D.; Giannoukos, G.; Earl, A. M.; Methe, B. A.; Sodergren, E. Evaluation of $16 \mathrm{~S}$ RDNA-Based Community Profiling for Human Microbiome Research. PLoS One 2012, 7, No. e39315.

(39) Bolger, A. M.; Lohse, M.; Usadel, B. Trimmomatic: A Flexible Trimmer for Illumina Sequence Data. Bioinformatics 2014, 30, 21142120.

(40) Magoc, T.; Salzberg, S. L. FLASH: Fast Length Adjustment of Short Reads to Improve Genome Assemblies. Bioinformatics 2011, 27, 2957-2963.

(41) Wang, Q.; Garrity, G. M.; Tiedje, J. M.; Cole, J. R. Näive Bayesian Classifier for Rapid Assignment of RRNA Sequences into the New Bacterial Taxonomy. Appl. Environ. Microbiol. 2007, 73, 5261-5267.

(42) Caporaso, J. G.; Kuczynski, J.; Stombaugh, J.; Bittinger, K.; Bushman, F. D.; Costello, E. K.; Fierer, N.; Peña, A. G.; Goodrich, J. K.; Gordon, J. I.; Huttley, G. A.; Kelley, S. T.; Knights, D.; Koenig, J. E.; Ley, R. E.; Lozupone, C. A.; McDonald, D.; Muegge, B. D.; Pirrung, M.; Reeder, J.; Sevinsky, J. R.; Turnbaugh, P. J.; Walters, W.
A.; Widmann, J.; Yatsunenko, T.; Zaneveld, J.; Knight, R. QIIME Allows Analysis of High-Throughput Community Sequencing Data. Nat. Methods 2010, 7, 335-336.

(43) Quast, C.; Pruesse, E.; Yilmaz, P.; Gerken, J.; Schweer, T.; Yarza, P.; Peplies, J.; Glöckner, F. O. The SILVA Ribosomal RNA Gene Database Project: Improved Data Processing and Web-Based Tools. Nucleic Acids Res. 2013, 41, D590-D596.

(44) Albertsen, M.; Karst, S. M.; Ziegler, A. S.; Kirkegaard, R. H.; Nielsen, P. H. Back to Basics - The Influence of DNA Extraction and Primer Choice on Phylogenetic Analysis of Activated Sludge Communities. PLoS One 2015, 10, No. e0132783.

(45) Legendre, P.; Gallagher, E. D. Ecologically Meaningful Transformations for Ordination of Species Data. Oecologia 2001, 129, 271-280.

(46) National Food Institute DTU. Danish (Q)SAR Database. National Food Institute, Technical University of Denmark. http:// qsardb.food.dtu.dk/database/index.html (accessed Apr 13, 2021).

(47) Liu, L.; Wu, F.; Haderlein, S.; Grathwohl, P. Determination of the Subcooled Liquid Solubilities of PAHs in Partitioning Batch Experiments. Geosci. Front. 2013, 4, 123-126.

(48) Schmidt, S. N.; Mayer, P. Linking Algal Growth Inhibition to Chemical Activity: Baseline Toxicity Required 1\% of Saturation. Chemosphere 2015, 120, 305-308.

(49) Winding, A.; Modrzyński, J. J.; Christensen, J. H.; Brandt, K. K.; Mayer, P. Soil Bacteria and Protists Show Different Sensitivity to Polycyclic Aromatic Hydrocarbons at Controlled Chemical Activity. FEMS Microbiol. Lett. 2019, 366, fnz214.

(50) Monferrán, M. V.; Echenique, J. R.; Wunderlin, D. A. Degradation of Chlorobenzenes by a Strain of Acidovorax Avenae Isolated from a Polluted Aquifer. Chemosphere 2005, 61, 98-106.

(51) Shehu, D.; Alias, Z. Dechlorination of Polychlorobiphenyl Degradation Metabolites by a Recombinant Glutathione S-Transferase from Acidovorax Sp. KKS102. FEBS Open Bio 2019, 9, 408419.

(52) Sohn, J. H.; Kwon, K. K.; Kang, J.-H.; Jung, H.-B.; Kim, S.-J. Novosphingobium Pentaromativorans Sp. Nov., a High-MolecularMass Polycyclic Aromatic Hydrocarbon-Degrading Bacterium Isolated from Estuarine Sediment. Int. J. Syst. Evol. Microbiol. 2004, 54, $1483-1487$.

(53) Liu, Z.-P.; Wang, B.-J.; Liu, Y.-H.; Liu, S.-J. Novosphingobium Taihuense Sp. Nov., a Novel Aromatic-Compound-Degrading Bacterium Isolated from Taihu Lake, China. Int. J. Syst. Evol. Microbiol. 2005, 55, 1229-1232.

(54) Gupta, S. K.; Lal, D.; Lal, R. Novosphingobium Panipatense Sp. Nov. and Novosphingobium Mathurense Sp. Nov., from OilContaminated Soil. Int. J. Syst. Evol. Microbiol. 2009, 59, 156-161.

(55) Dangmann, E.; Stolz, A.; Kuhm, A. E.; Hammer, A.; Feigel, B.; Noisommit-Rizzi, N.; Rizzi, M.; Reuß, M.; Knackmuss, H.-J. Degradation of 4-Aminobenzenesulfonate by a Two-Species Bacterial Coculture. Biodegradation 1996, 7, 223-229.

(56) Yan, Z.; Zhang, Y.; Wu, H.; Yang, M.; Zhang, H.; Hao, Z.; Jiang, $H$. Isolation and Characterization of a Bacterial Strain Hydrogenophaga Sp. PYR1 for Anaerobic Pyrene and Benzo[a]Pyrene Biodegradation. RSC Adv. 2017, 7, 46690-46698.

(57) Saha, S.; Badhe, N.; Pal, S.; Biswas, R.; Nandy, T. Carbon and Nutrient-Limiting Conditions Stimulate Biodegradation of Low Concentration of Phenol. Biochem. Eng. J. 2017, 126, 40-49. 